\title{
Determinação do perfil fitoquímico e avaliação de atividades biológicas de extratos de folhas de Ilex brevicuspis Reissek. (Aquifoliaceae)
}

Determination of the phytotochemical profile and evalution of biological activities of leaf extracts of Ilex brevicuspis Reissek. (Aquifoliaceae)

Determinación del perfil fitoquímico y evaluación de actividades biológicas de extractos de hojas Ilex brevicuspis Reissek. (Aquifoliaceae)

Ana Paula Mallman

ORCID: https://orcid.org/0000-0001-7568-8637 Universidade Estadual do Oeste do Paraná, Brasil E-mail: ap.mallmann@ hotmail.com

Camila Vogt dos Santos ORCID: https://orcid.org/0000-0001-7566-8003 Universidade Estadual do Oeste do Paraná, Brasil E-mail: cami_vogt@hotmail.com

Adrieli Gorlin Toledo

ORCID: https://orcid.org/0000-0002-0199-8330 Universidade Estadual do Oeste do Paraná, Brasil E-mail: adrieligorlin@live.com

Larissa Valéria Lakoski

ORCID: https://orcid.org/0000-0001-8185-3790 Universidade Estadual do Oeste do Paraná, Brasil E-mail: adrieligorlin@live.com

Débora Marina Bandeira

ORCID: https://orcid.org/0000-0001-5956-7210 Universidade Estadual do Oeste do Paraná, Brasil E-mail: dm-bandeira@hotmail.com

Juliana Moço Corrêa

ORCID: https://orcid.org/0000-0003-4526-0060 Universidade Estadual do Oeste do Paraná, Brasil E-mail: juliana.correa2@unioeste.br

Fabiana Gisele da Silva Pinto ORCID: https://orcid.org/0000-0002-0486-8486 Universidade Estadual do Oeste do Paraná, Brasil E-mail: fabiana.pinto@unioeste

\begin{abstract}
Resumo
O gênero Ilex compreende mais de 500 espécies sendo considerada uma fonte promissora para a extração de princípios ativos com diversas atividades biológicas. Diante desse foco, este trabalho utilizou folhas de Ilex brevicuspis Reissek para produção de extratos, objetivando a determinação fitoquímica, antioxidante, antibacteriana e acaricida sobre Dermanyssus gallinae (Degeer, 1778). As folhas foram coletadas, secas e trituradas em moinho, e seus extratos produzidos com diferentes solventes, etanol (EE), metanol (EM), acetato de etila (EAE) e água destilada (Eaq). As análises fitoquímicas revelaram três grupos de compostos: saponinas, esteroides e taninos. Os extratos apresentaram atividade inibitória e bactericida para cepas padrões (Gram-negativas e positivas) e para dez sorotipos de Salmonella spp. O extrato EM apresentou os melhores resultados de CIM para as cepas padrões, variando de 6,25 $\mathrm{mg} / \mathrm{mL}$ a $50 \mathrm{mg} / \mathrm{mL}$ e para CBM de $6,25 \mathrm{mg} / \mathrm{mL}$ a $100 \mathrm{mg} / \mathrm{mL}$. Para os sorotipos de Salmonella o extrato EE apresentou a melhor atividade antibacteriana, variando de $25 \mathrm{mg} / \mathrm{mL}$ a $50 \mathrm{mg} / \mathrm{mL}$ para CIM e $200 \mathrm{mg} / \mathrm{mL}$ para CBM. O extrato EM revelou elevada atividade acaricida de $94 \%$ e moderada capacidade antioxidante de $81,45 \%$. Os ensaios demonstraram que os extratos EM e EE de I. brevicuspis representam um potencial alternativo para controle de bactérias e ácaros, demonstrando uma nova perspectiva para desenvolvimento de produtos naturais a partir de uma espécie nativa.
\end{abstract}

Palavras-chave: Atividade antimicrobiana; Compostos bioativos; Atividade antioxidante; DPPH, Dermanyssus gallinae. 


\begin{abstract}
The genus Ilex comprises about 500 species being considered a promising source for the extraction of active principles with different biological activities. Before this approach, this work used Ilex brevicuspis Reissek leaves for the production of extracts, aiming the phytochemical, antioxidant, antimicrobial and acaricide determination in Dermanyssus gallinae (Degeer, 1778). The leaves were collected, dried and ground in a mill, and their extracts produced with different solvents: ethanol (EE), methanol (EM), ethyl EAEate (EAE) and water (Eaq). Phytochemical analyses revealed three groups of compounds: saponins, steroids and tannins. The extracts showed inhibitory and bactericidal activity for standard strains (Gram-negative and positive) and for ten serotypes of Salmonella spp. The EM extract showed the best MIC results for the standard strains, ranging from $6.25 \mathrm{mg} / \mathrm{mL}$ to $50 \mathrm{mg} / \mathrm{mL}$ and for MBC from $6.25 \mathrm{mg} / \mathrm{mL}$ to $100 \mathrm{mg} / \mathrm{mL}$. For serotypes of Salmonella, EE extract presented the best activity, varying from $25 \mathrm{mg} / \mathrm{mL}$ to $50 \mathrm{mg} / \mathrm{mL}$ for MIC and $200 \mathrm{mg} / \mathrm{L}$ for MBC. EM extract showed a high acaricidal activity of $94 \%$ and moderate antioxidant capacity of $81.45 \%$. Assays demonstrated that EM and EE extracts of I. brevicuspis represent an alternative potential for the control of bacteria and mites, demonstrating a new perspective for the future development of natural products from a native species.
\end{abstract}

Keywords: Antimicrobial activity; Bioactive compounds; Antioxidante activity; DPPH, Dermanyssus gallinae.

\title{
Resumen
}

El género Ilex compreende másde 500 especies siendo considerado una fuente prometedora para la extracción de principios activos con diferentes actividades biológicas. Dado este enfoque, este trabajo utilizó hojas de Ilex brevicuspis Reissek para la producción de extractos, con el objetivo de la determinación fitoquímica, antioxidante, antimicrobiana y acaricida en Dermanyssus gallinae (Degeer, 1778). Las hojas se recolectaron, secaron y trituraron en un molino, y sus extractos se produjeron con diferentes solventes: etanol (EE), metanol (EM), acetato de etilo (EAE) y agua (Eaq). Los análisis fitoquímicos revelaron tres grupos de compuestos: saponinas, esteroides y taninos. Los extractos mostraron actividad inhibidora y bactericida para cepas (Gram negativas y positivas) y para diez Salmonella spp. El extracto de EM mostró los mejores resultados de CIM para las cepas estándar, con un rango de $6.25 \mathrm{mg} / \mathrm{mL}$ a $50 \mathrm{mg} / \mathrm{mL}$ y para CBM de $6.25 \mathrm{mg} / \mathrm{mL}$ a $100 \mathrm{mg} / \mathrm{mL}$. Para los serotipos de Salmonella, el extracto de EE mostró la mejor actividad, con un rango de $25 \mathrm{mg} / \mathrm{mL}$ a $50 \mathrm{mg} / \mathrm{mL}$ para MIC y $200 \mathrm{mg} / \mathrm{mL}$ para CBM. El extracto de EM mostró una alta actividad acaricida del $94 \%$ y una moderada capacidad antioxidante del 81,45\%. Las pruebas demostraron que los extractos de EM y EE de I. brevicuspis representan un potencial alternativo para el control de bacterias y ácaros, demostrando una nueva perspectiva para el desarrollo futuro de productos naturales de una especie nativa.

Palabras clave: Actividad antimicrobiana; Compuestos bioactivos; Actividad antioxidante; DPPH, Dermanyssus gallinae.

\section{Introdução}

As plantas apresentam diversos componentes químicos envolvidos naturalmente no seu metabolismo secundário e estes podem ser potenciais fontes de compostos bioativos. Aproximadamente $40 \%$ dos novos medicamentos, que estão atualmente disponíveis, derivam direta ou indiretamente de fontes naturais vegetais (Guilarducci et al., 2016). Os produtos naturais, como extratos vegetais, têm sido utilizados como aditivos fitogênicos na alimentação de animais confinados, com o objetivo de melhorar o desempenho das aves comerciais e otimizar a produção avícola (Fascina, 2011). Além disso, a utilização de fitogênicos como aditivos alimentares, não deixa resíduos químicos como a exemplo os antibióticos sintéticos, tornando-se mais seguro para o uso em larga escala (Brenes \& Roura, 2010).

Além disso, o aumento de pesquisas relacionadas a esses compostos vegetais está diretamente relacionado com a elevada resistência a antimicrobianos convencionais, que é atualmente um dos mais relevantes problemas na saúde pública, visto que o uso inapropriado, incluindo as quantidades exacerbadas utilizadas, tem causado aumento da incidência de microrganismos resistentes (Freitas et al., 2014; Loureiro et al., 2016).

Outra utilização de bioativos vegetais está relacionada ao setor avícola como alternativa ao uso de compostos químicos no controle de pragas, como Dermanyssus gallinae (Acari: Dermanyssidae), conhecido como a principal praga relacionada aos aviários de poedeiras e que causam grandes danos a esses animais, como: irritação, inquietação, anemia, interferindo assim na produção e qualidade dos ovos e até mesmo levar a morte do animal (Fochlay et al., 2017). 
Vários estudos apontam também que alguns compostos bioativos de plantas podem vir a substituir, ou mesmo diminuir a quantidade de conservantes sintéticos utilizados nas indústrias. Para isso, é de grande importância a avaliação de suas atividades biológicas para que seja verificado o seu uso de forma segura. Neste sentido, é necessário pesquisar o princípio ativo, e conhecer seus efeitos adversos, como toxicidade, potencial carcinogênico, antioxidante, entre outros (Gonçalves et al., 2015).

Ilex brevicuspis Reissek pertence à família Aquifoliaceae, é uma árvore nativa do sul do Brasil, conhecida popularmente como caúna da serra, congonha ou orelha e são escassos os relatos na literatura sobre suas atividades biológicas. A espécie mais estudada deste gênero é a Ilex paraguaiensis (erva-mate) comumente utilizada na forma de chás, que apresenta diversas propriedades biológicas, como atividade antioxidante, antiobesidade e atividade antimicrobiana (Arçari et al., 2009).

Vários fitoquímicos biologicamente ativos estão presentes no grupo de plantas Ilex spp. que podem promover benefícios a saúde, como compostos fenólicos (ácidos clorogênicos) e metilxantinas (cafeína e teobromina), flavonóides (rutina, quercetina e kaempferol), saponinas, aminoácidos, minerais ( P, Fe e Ca) e vitaminas (C, B1 e B2) (Heck \& de Mejia, 2007). Nesse aspecto de saúde, o gênero demonstra diferentes potencialidades terapêuticas e nutricional, porém ainda é incipiente pesquisas do ponto de vista de uso destes compostos bioativos no controle de microrganismos patogênicos e pragas urbanas.

Diante deste panorama, o objetivo desse estudo foi determinar o perfil fitoquímico dos extratos vegetais das folhas de I. brevicuspis, bem como avaliar seu potencial antibacteriano sobre cepas padrões microbianas e de Salmonella spp, além da atividade antioxidante e ação acaricida contra D. gallinae.

\section{Metodologia}

A pesquisa foi realizada in vitro em condições controladas e aplicou-se o método quantitativo. Como existem dúvidas sobre a ação dos extratos vegetais sobre as bactérias e ácaros, optou-se pelo método hipotético-dedutivo (Pereira et al., 2018).

\subsection{Coleta e identificação das folhas de Ilex brevicuspis}

A coleta das folhas foi realizada no parque ecológico Paulo Gorski, localizado no município de Cascavel, região oeste do estado do Paraná, $24^{\circ} 57^{\prime} 51.61^{\prime \prime S}$ e 53²6'14.80"O. A planta usada neste estudo foi encaminhada para identificação e após confirmação da espécie para Ilex brevicuspis foi depositada com o voucher UNOP 8924 no Herbário da Universidade Estadual do Oeste do Paraná/UNIOESTE.

\subsection{Secagem e obtenção do material vegetal}

Após a coleta o material vegetal foi seco em estufa de circulação de ar a $40^{\circ} \mathrm{C}$, por 48 horas, e posteriormente foi moído em moinho de facas do tipo Willey com granulometria de $0,42 \mathrm{~mm}$. O pó obtido foi armazenado em recipientes de vidro fechado e ao abrigo de luz até o uso para produção dos extratos. O rendimento dos extratos vegetais foi calculado pela equação 1.

$$
\text { Porcentagem }(\%)=\frac{\text { massa do extrato }(g)}{\text { massa vegetal seca e moída }(g)} X 100
$$

\subsection{Obtenção dos extratos vegetais}

Foi realizada a metodologia de Pandini et al. (2015) com modificações. O material vegetal seco (10g) e $100 \mathrm{~mL}$ dos solventes: água destilada (EAq), metanol P.A. (EM), etanol P.A. (EE) e acetato de etila P.A. (EAE), foram mantidos em 
agitador rotativo à $220 \mathrm{rpm}$ durante 24 horas. Após este período, a solução foi filtrada utilizando papel filtro Whatman $\mathrm{n}^{\mathrm{o}} 1 \mathrm{e}$ centrifugada a 5000 rpm durante 15 minutos a temperatura ambiente. Posteriormente, foram submetidas à rotaevaporação para total eliminação dos solventes, exceto o extrato aquoso, obtendo um extrato bruto ao final do processo. $\mathrm{O}$ extrato foi armazenado ao abrigo da luz em freezer a $4^{\circ} \mathrm{C}$.

\subsection{Trigagem fitoquímica}

Os testes fitoquímicos para a detecção da presença de alcalóides, saponinas, esteróides, triterpenóides, antocianinas, antocianidinas, flavonoides, taninos e cumarinas foram realizados de acordo com a metodologia desenvolvida por Matos (1997) com modificações.

\subsection{Microrganismos utilizados}

Os ensaios experimentais foram realizados no Laboratório de Microbiologia e Biotecnologia (LAMIBI) da Universidade Estadual do Oeste do Paraná (UNIOESTE), Campus de Cascavel/PR. Para os ensaios foram utilizados diferentes microrganismos padrões identificados, sendo seis cepas Gram negativas: Escherichia coli (ATCC 25922), Salmonella Enteritidis (ATCC 13076), Salmonella Typhimurium (ATCC 14028), Pseudomonas aeruginosa (ATCC 27853), Proteus mirabilis (ATCC 25933) e Klebsiella pneumoniae (ATCC 13883), quatro Gram-positivas: Staphylococcus aureus (ATCC 25923), Enterococcus faecalis (ATCC 19433), Staphylococcus epidermidis (ATCC 12228) e Bacillus subtillis (CCD-04). Foram testados também, 10 sorotipos de Salmonella enterica de maior ocorrência na região Oeste do Paraná, Brasil, isoladas de aviários de frango de corte da região, sendo: $S$. Enteritidis, $S$. Infantis, $S$. Typhimurium, $S$. Heildelberg, $S$. Gallinarum, $S$. Mbandaka, $S$. Give, $S$. Saintpaul, S. Orion e $S$. Agona, cedidos por um laboratório veterinário de Cascavel, Paraná, Brasil (SCUR et al., 2014).

Para o teste de atividade antimicrobiana, as bactérias foram recuperadas em caldo de enriquecimento Brain Heart Infusion (BHI) e incubados por $24 \mathrm{~h}$ a $36 \pm 0,1^{\circ} \mathrm{C}$. Após este período, as cepas foram repicadas em meio Ágar Muller Hinton $(\mathrm{AMH})$, e padronizadas em solução salina $(0,85 \%)$ resultando na concentração final de $1 \times 10^{5} \mathrm{UFC} / \mathrm{mL}$ de acordo com a escala Mac Farland.

\subsection{Concentração inibitória mínima (CIM)}

Os ensaios foram realizados pelo método de microdiluição em caldo conforme as normas do Clinical and Laboratory Standards Institute (2015) e Scur et al. (2014), em placas de 96 poços. Para a determinação da CIM dos extratos vegetais foram adicionados $150 \mu \mathrm{L}$ de caldo Müller-Hinton (MH) em todos os poços, $150 \mu \mathrm{L}$ dos extratos vegetais foi acrescentado no primeiro poço, e foi realizada diluições seriadas com concentrações variando de 200 até $0,09 \mathrm{mg} / \mathrm{mL}$ nos poços posteriores. Após as diluições, foram distribuídas alíquotas de $10 \mu \mathrm{L}$ com microrganismos em cada poço e as placas foram incubadas a $36^{\circ} \mathrm{C}$ durante 24 horas.

Para o controle negativo foi utilizado o antibiótico comercial gentamicina $(200 \mathrm{mg} / \mathrm{mL}$. Como controle positivo foi adicionado o inóculo ao caldo $\mathrm{MH}$, sem presença do extrato para verificar a viabilidade do microrganismo testado. Também foi realizado o controle de esterilidade dos extratos solubilizados em metanol P.A. e um controle do diluente metanol para verificar se houve interferência no ensaio. Após a incubação, foi utilizado $10 \mu \mathrm{L}$ da solução de cloreto de trifeniltetrazólio (TTC) a $0,5 \%$ como revelador colorimétrico para cada poço da placa. A CIM foi realizada em triplicata, sendo possível determinar a menor concentração dos extratos capaz de inibir o crescimento bacteriano. 


\subsection{Concentração bactericida mínima (CBM)}

Após a realização do ensaio da CIM, antes da adição de TTC, foi retirada uma alíquota de $2 \mu \mathrm{L}$ de cada poço e inoculada em placas com $\mathrm{MH}$. As placas foram incubadas durante 24 horas a temperatura de $36^{\circ} \mathrm{C}$. Após este período, foi observado se houve crescimento bacteriano na placa, para então determinar qual foi a menor concentração dos extratos vegetais capaz de causar a morte dos microrganismos. A CIM e a CBM dos extratos vegetais foram classificadas de acordo com Pandini et al. (2015), sendo a atividade enquadrada em uma das 4 classes: elevada $(12,5 \mathrm{mg} / \mathrm{mL})$, moderada $(12,5$ a 25 $\mathrm{mg} / \mathrm{mL}$ ), baixa (50 a $100 \mathrm{mg} / \mathrm{mL}$ ) e muito baixa (>100 mg/mL).

\subsection{Atividade antioxidante}

A atividade antioxidante foi realizada de acordo com as metodologias propostas por Rufino et al. (2007) e Weber et al. (2014), pelo método da redução do radical livre 2,2-difenil-1-picril-hidrazila (DPPH). Uma alíquota de 0,1 mL dos extratos $(1,75 \mathrm{mg} / \mathrm{mL}$ a $35 \mathrm{mg} / \mathrm{mL})$ foi tratada com $3,9 \mathrm{~mL}$ de solução metanólica de DPPH $0,2 \mathrm{mM}$ e levemente homogeneizadas. A solução foi deixada em repouso ao abrigo de luz durante 30 minutos. As amostras foram mensuradas em espectrofotômetro com absorbância de $515 \mathrm{~nm}$. Como controle negativo foi utilizado $0,1 \mathrm{~mL}$ de solução controle (álcool metílico, acetona e água). Para controle positivo foi utilizado o antioxidante butil-hidroxi-tolueno (BHT). A calibração do espectrofotômetro foi realizada com álcool metílico. O cálculo da capacidade de sequestro do radical livre foi expresso pela equação 2, onde $\mathrm{Abs}_{0}$ é a absorbância do controle e Abs 1 é a absorbância da amostra. Os testes foram realizados em triplicata.

$$
I \%: \frac{A b s 0-A b s 1}{A b s 0} \times 100
$$

\subsection{Atividade acaricida}

Para o pré-teste de atividade acaricida de aplicação tópica, os ácaros foram coletados em aviário de postura comercial, sem histórico de utilização de acaricidas, localizado na região Oeste do estado do Paraná, Brasil, sendo o experimento realizado no mesmo dia da coleta. Os extratos vegetais foram solubilizados em acetona nas concentrações de $10 \%, 7,5 \%, 5 \%$ e 2,5\%. Para a aplicação dos extratos, trinta fêmeas ingurgitadas e ativas foram acondicionadas em papel filtro estéril $(1 \times 1,5 \mathrm{~cm})$ parcialmente dobrados ao meio para a aglomeração dos ácaros, sendo aplicado $20 \mu \mathrm{L}$ dos extratos, em 5 repetições. Posteriormente, os ácaros foram incubados em tubos de fundo chato fechados com tampão de algodão hidrofóbicos e tecido voil. Foi realizado um controle, com o mesmo número de ácaros e repetições, aplicando $20 \mu \mathrm{L}$ de acetona. Após 48 horas foi analisada a mortalidade, sendo que os ácaros que não se moviam ao serem tocados com um pincel foram considerados mortos. Os dados foram analisados por teste ANOVA fatorial, seguido de teste de acompanhamento KruskalWallys para dados não paramétricos, para comparação entre as médias dos extratos utilizando o programa Statistica 7.0, para determinar a diferença da mortalidade dos tratamentos, com nível de significância de 5\%.

\section{Resultados e Discussão}

\subsection{Triagem fitoquímica}

Os extratos vegetais de Ilex brevicuspis preparados com diferentes solventes, apresentaram os seguintes rendimentos: EAE (4,3\%), EE (13\%), EM (22\%) e EAq (47,47\%). Vários são os fatores capazes de influenciar no rendimento dos extratos vegetais, tais como temperatura, tempo de extração, mas principalmente o solvente utilizado, sendo que sua polaridade e solubilidade influenciam diretamente sobre o rendimento dos mesmos (Cabana et al., 2013; Fernández-Agulló et al., 2013). 
De acordo com a determinação fitoquímica, os extratos vegetais EAE, EE e EM demonstraram a presença dos compostos das classes: saponina, esteroides triterpenoides, e esteroides livres. O EM apresentou maior diversidade de grupos metabólitos secundários, contendo as três classes de compostos já citados, além dos taninos condensados e o EAq apresentou somente a classe das saponinas (Tabela 1).

Tabela 1 - Prospecção fitoquímica dos metabólitos secundários presentes nos extratos vegetais foliares de Ilex brevicuspis Reissek.

\begin{tabular}{lcccc}
\hline $\begin{array}{l}\text { Metabólitos } \\
\text { secundários }\end{array}$ & EAq & EAE & EE & EM \\
\hline Saponinas & + & + & + & + \\
Esteróides \\
Triterpenoides & - & + & + & + \\
Esteróides livres & - & + & + & + \\
Triterpenoides & - & - & - & - \\
Alcaloides & - & - & - & - \\
Antocianinas & - & - & - & - \\
Antocianidinas & - & - & - & - \\
Flavonas & - & - & - & - \\
Flavanóis & - & - & - & - \\
Xantonas & - & - & - & - \\
Chalconas & - & - & - & - \\
Auronas & - & - & - & - \\
Flavonóides & - & - & - & + \\
Taninos condensados & - & - & - & - \\
Cumarinas & - & & & - \\
\hline
\end{tabular}

+ Presença; - Ausência; Extrato aquoso (EAq); Extrato metanólico (EM); Extrato etanólico (EE) e Extrato de acetato de etila (EAE). Fonte: Autores.

Dentro do gênero Ilex, as classes de metabólitos secundários mais comumente encontradas quando extraídos com etanol e em água são saponinas e os compostos fenólicos, como ácidos fenólicos e flavonoides (Filip et al., 2000; Taketa et al., 2002; Costa et al., 2017). O que corrobora com o nosso estudo, visto que também foram encontrados saponinas e taninos (contidos na classe dos compostos fenólicos). Além disso, pesquisas sobre a composição química completa de extratos de $I$. brevicuspis não foram reportadas na literatura, apenas um estudo semelhante a este foi desenvolvido por Taketa et al. (2002) que detectou a presença de triterpenos e triterpenoides do extrato etanólico dessa espécie pela prospecção fitoquímica.

A variação de classes de compostos verificado em diferentes espécies está relacionada com diversos fatores como sazonalidade, temperatura, disponibilidade hídrica, altitude, ritmo circadiano, poluição atmosférica e interação com o ambiente, que podem afetar a via metabólica e, consequentemente, influenciar nos compostos produzidos pela planta (GobboNeto; Lopes, 2007).

\subsection{Atividade antimicrobiana (CIM/CBM)}

A variação na atividade antimicrobiana observada no estudo foi dependente do solvente extrator e do microrganismo testado, e os dados foram classificados conforme Pandini et al., (2015). O EM apresentou os melhores resultados de CIM (12,5 $\mathrm{mg} / \mathrm{mL}$ e $200 \mathrm{mg} / \mathrm{mL}$ ), sendo que sua atividade apresentou grande variação, foi classificada de elevada a muito baixa, para as cepas padrões testadas, apresentando atividade elevada para cepas Gram-positivas. Para o EE verificou-se atividade considerada moderada a muito baixa $(12,5 \mathrm{mg} / \mathrm{mL}$ e $200 \mathrm{mg} / \mathrm{mL})$, apresentando as maiores atividades inibitórias e bactericidas para E. coli e $S$. aureus, S. epidermidis. Já o EAE demonstrou CIM e CBM variando entre moderada e muito baixa (12,5 $\mathrm{mg} / \mathrm{mL}$ e $200 \mathrm{mg} / \mathrm{mL}$ ) apresentando o melhor resultado para S. epidermidis, (CIM de 12,5 mg/mL e CBM de $100 \mathrm{mg} / \mathrm{mL}$ ). 
Dentre todos os extratos testados, o EAq apresentou os menores valores para todos os microrganismos, tendo sua atividade variando de baixa a muito baixa $(50 \mathrm{mg} / \mathrm{mL}$ e $200 \mathrm{mg} / \mathrm{mL})$ e não apresentou atividade inibitória ou bactericida para as cepas $E$. faecalis e K. pneumoniae; corroborando com Lima et al. (2021) que ressalta que os metabólicos que melhor exibem potencial antibacteriano em extratos vegetais apresentam em sua composição a combinação de saponinas, flavanóides e taninos, e neste estudo somente a presença de saponinas foi detectado em EAq. Os extratos aquosos de erva-mate no estudo de Fayad et al. (2020) apresentaram atividade antibacteriana apenas sobre S. aureus $(3,75 \mathrm{mg} / \mathrm{mL})$ quando comparado ao antibiótico gentamicina.

Já para os sorotipos de Salmonella, o EE apresentou atividade inibitória entre moderada e baixa, seguido do EM, com atividade entre baixa e muito baixa, e os EAE e EAq apresentaram atividades consideradas muito baixas (Tabela 2).

Tabela 2 - Concentração inibitória mínima (CIM) e concentração bactericida mínima (CBM) em mg/mL dos extratos foliares de Ilex brevicuspis frente a diferentes cepas padrão e sorotipos de Salmonella spp.

\begin{tabular}{lcccc}
\hline $\begin{array}{l}\text { Cepas } \\
\text { Bactérias }\end{array}$ & $\begin{array}{c}\text { EM } \\
\text { (CIM / CBM } \\
\mathbf{m g} / \mathbf{m L})\end{array}$ & $\begin{array}{c}\text { EE } \\
\text { (CIM / CBM } \\
\mathbf{m g} / \mathbf{m L})\end{array}$ & $\begin{array}{c}\text { EAE } \\
(\mathbf{C I M} / \mathbf{C B M} \\
\mathbf{m g} / \mathbf{m L})\end{array}$ & $\begin{array}{c}\text { EAq } \\
\text { (CIM / CBM } \\
\mathbf{~ m g / m L})\end{array}$ \\
\hline Gram-positivas & & & & \\
\hline S. aureus & $3,12 / 6,25$ & $12,5 / 100$ & $25 / 100$ & $200 / 200$ \\
S. epidermidis & $12,5 / 100$ & $12,5 / 200$ & $12,5 / 100$ & $100 /-$ \\
B. subtilis & $6,25 / 12,5$ & $50 / 200$ & $25 / 50$ & $200 /-$ \\
E. faecalis & $50 / 100$ & $100 /-$ & $-/-$ & $-/-$ \\
\hline Gram-negativas & & & & $50 /-$ \\
\hline E. coli & $50 / 200$ & $12,5 / 100$ & $25 / 100$ & $50 / 200$ \\
P. aeruginosa & $6,25 / 50$ & $50 / 100$ & $25 / 50$ & $-/-$ \\
K. pneumoniae & $200 / 200$ & $50 / 200$ & $200 /-$ & $100 / 200$ \\
P. mirabilis & $12,5 / 50$ & $100 / 200$ & $200 /-$ & \\
\hline Salmonella & & & & $200 / 200$ \\
& & & & $200 / 200$ \\
\hline S. Agona & $100 /-$ & $50 /-$ & $200 /-$ & $200 / 200$ \\
S. Santpaul & $100 / 200$ & $25 / 200$ & $200 /-$ & $200 / 200$ \\
S. Heidelberg & $100 /-$ & $25 / 200$ & $100 / 200$ & $200 / 200$ \\
S. Orion & $50 / 200$ & $25 / 200$ & $200 / 200$ & $200 / 200$ \\
S. Give & $100 / 200$ & $25 /-$ & $50 / 200$ & $200 / 200$ \\
S. Gallinarium & $50 / 200$ & $25 /-$ & $50 / 200$ & $100 / 200$ \\
S. Mbandaka & $100 /-$ & $50 / 200$ & $200 / 200$ & $200 / 200$ \\
S. Infantis & $100 /-$ & $50 /-$ & $200 /-$ & \\
S. Typhimurium & $50 /-$ & $50 /-$ & $200 / 200$ & \\
S. Enteritidis & $100 /-$ & $50 /-$ & $200 /-$ & \\
\hline
\end{tabular}

(-) Sem atividade. Extrato aquoso (EAq); Extrato metanólico (EM); Extrato etanólico (EE) e Extrato de acetato de etila (EAE). Fonte: Autores.

Nossos resultados estão de acordo com os encontrados na literatura para extratos de Ilex spp. Pode-se evidenciar a inibição de $P$. mirabilis e E. coli quando submetidas ao extrato etanólico de Ilex paraguarienses, sendo indicado o uso do extrato na concentração de $400 \mathrm{mg} / \mathrm{mL}$ (Costa et al., 2017), também a atividade antimicrobiana dos extratos hexânico e aquoso de Ilex paraguarienses frente a K. pneumoniae, P. aeruginosa e S. aureus (Penteado et al., 2016). Além de também ter sido relatada a atividade antimicrobiana de Ilex latifolia frente a $S$. aureus (CIM $100 \mathrm{mg} / \mathrm{mL}$ ), P. aeruginosa (CIM $100 \mathrm{mg} / \mathrm{mL}$ ), E. coli (CIM $100 \mathrm{mg} / \mathrm{mL}$ ) (LI et al., 2013).

A elevada atividade do EM pode estar relacionada com a presença de taninos na sua composição, sendo um grupo com comprovada atividade antimicrobiana. Foram encontrados taninos condensados que apresentam uma ampla diversidade na sua 
estrutura, diversidade de posições entre suas ligações (Monteiro et al., 2005). Seu modo de ação pode estar relacionado à formação de complexos com enzimas e proteínas microbianas, levando assim a uma inativação das suas funções, inibindo o transporte de elétrons através de membranas, ou ainda causar alterações em íons relacionados a atividades de algumas enzimas essenciais a célula, o que thes confere a sua elevada atividade antimicrobiana (Mendez et al., 2012; Gyawali; Ibrahim, 2014).

Já a atividade antimicrobiana dos EAq, EAE e EE pode ser atribuída a presença das saponinas na sua composição. Esses compostos são sintetizados a partir da via isoprenóide do metabolismo secundário de plantas, e foram identificadas nos extratos do presente estudo, e já apresentam ação antimicrobiana relatada, agindo sobre a membrana celular bacteriana, formando complexos com os esteróis e produzindo grandes poros, que alteram sua permeabilidade, causando danos ao microrganismo (Puentes, 2009).

A detecção de alguma classe de composto nos extratos e a não observação de atividade antimicrobiana do mesmo, sugerem que alternativamente esses extratos se combinado seu uso a antibióticos, podem exibir efeito sinérgico potencializando ação antibacteriana, embora o mecanismo pelo qual isso ocorre ainda não tenha sido elucidado (Santos et al., 2020).

\subsection{Atividade antioxidante}

O EM apresentou os melhores resultados de capacidade de sequestro do radical DPPH, com 81,45\% de atividade antioxidante quando testado a $10 \mathrm{mg} / \mathrm{mL}$. Os EE e EAq atingiram porcentagem de atividade antioxidante acima de $70 \%$ e $61 \%$ nas concentrações de 30 e $35 \mathrm{mg} / \mathrm{mL}$, respectivamente. Já o EAE apresentou cerca de $65 \%$ de atividade quando testado a $15 \%$. (Tabela 3).

Tabela 3 - Porcentagem de atividade antioxidante dos extratos vegetais foliares de Ilex brevicuspis por sequestro do radical DPPH.

\begin{tabular}{cccccc}
\hline $\begin{array}{c}\text { Concentração } \\
(\mathbf{m g} / \mathbf{m L})\end{array}$ & $\begin{array}{c}\text { Controle } \\
\text { BHT }\end{array}$ & EM & EE & EAE & EAq \\
\hline $\mathbf{3 5}$ & - & - & - & - & $61,62 \pm 0,87$ \\
$\mathbf{3 0}$ & - & - & $70,37 \pm 0,56$ & - & $48,08 \pm 0,78$ \\
$\mathbf{2 5}$ & - & - & $51,75 \pm 0,86$ & - & $30,87 \pm 0,84$ \\
$\mathbf{2 0}$ & - & - & $32,83 \pm 0,63$ & - & $19,78 \pm 0,82$ \\
$\mathbf{1 5}$ & - & - & $18,54 \pm 0,75$ & $65,20 \pm 0,64$ & - \\
$\mathbf{1 0}$ & - & $81,45 \pm 0,68$ & - & $48,48 \pm 1,21$ & - \\
$\mathbf{5}$ & - & $68,72 \pm 2,13$ & - & $35,53 \pm 0,83$ & - \\
$\mathbf{2}$ & - & $52,35 \pm 0,85$ & - & $20,18 \pm 0,69$ & - \\
$\mathbf{1 , 7 5}$ & & $31,34 \pm 0,73$ & - & - & - \\
$\mathbf{1}$ & $98,57 \pm 0,54$ & - & - & - & - \\
$\mathbf{0 , 5}$ & $77,32 \pm 0,67$ & - & - & - & - \\
$\mathbf{0 , 2 5}$ & $54,46 \pm 4,69$ & - & - & - & - \\
$\mathbf{0 , 1}$ & $37,85 \pm 2,99$ & - & - & - & - \\
\hline
\end{tabular}

(-) não testado; média \pm desvio padrão. Extrato aquoso (EAq); Extrato metanólico (EM); Extrato etanólico (EE) e Extrato de acetato de etila (EAE). Fonte: Autores.

Não foram encontrados relatos da atividade antioxidante de I. brevicuspis pelo método do sequestro do radical do DPPH. No entanto, foi relatada a atividade antioxidante dos extratos aquosos de outras espécies de Ilex, I. paraguariensis, I. dumosa, I. argentina, I. theezans, e I. pseudobuxus, a partir do método de oxidação de lipossomos oxidados por dicloridrato de 2,2'-Azobis (2-amidinopropano) (AAPH) e os extratos apresentaram compostos fenólicos na sua composição, o que justifica a presença de atividade antioxidante (Filip et al., 2000). 
A atividade antioxidante de I. paraguarienses foi verificada na literatura, sendo testados EAq e hidroalcoolico de folhas "in natura" secas e cancheadas, e o resultado variou de $28 \%$ a $48 \%$, o que torna os nossos resultados promissores, tendo em vista que I. brevicuspis apresentou um maior percentual de atividade antioxidante (Efing et al., 2009).

Muitas pesquisas relacionadas à atividade antioxidante de produtos naturais têm sido realizadas com o intuito de substituir os antioxidantes sintéticos, uma vez que esses podem ser potencialmente tóxicos. A atividade antioxidante de produto a base de plantas está relacionada com os compostos que são capazes de proteger o sistema biológico das plantas contra um potencial efeito dos processos oxidativos (Fernández-Agulló et al., 2013). A atividade antioxidante pode variar de acordo com os solventes utilizados para a extração do material vegetal, e também conforme sua polaridade e solubilidade (Fernández-Agulló et al., 2013; Onivogui et al., 2016).

\subsection{Atividade acaricida}

De acordo com o pré-teste tópico para a atividade acaricida, observou-se que o EM apresentou a maior percentagem de mortalidade (94\%) quando aplicado a 10\%, seguido pelos EE $(79,33 \%)$ e EAE $(76,66 \%)$ que não apresentaram diferença estatística entre si. O mesmo padrão de resposta foi observado quando aplicado na concentração a 7,5\%, sendo que EM apresentou maior porcentagem de mortalidade, com 77,30\%, seguido pelos EE (56\%) e EAE (57,33\%). Para as concentrações de $5 \%$ e 2,5\%, as porcentagens de mortalidade observadas variaram de $46 \%$ a $10 \%$. Somente EAq não apresentou atividade acaricida sobre D. gallinae (Tabela 4).

Tabela 4 - Porcentagem de mortalidade de Dermanyssus gallinae após 48 horas de contato tópico com extratos vegetais das folhas de Ilex brevicuspis.

\begin{tabular}{lccc}
\hline \multirow{2}{*}{ Concentração Extrato \% } & \multicolumn{3}{c}{ Mortalidade $(\%)$} \\
\cline { 2 - 4 } $0^{*}$ & $0,00 \pm 0,00$ & EE & EAE \\
\cline { 2 - 4 } 2,5 & $20,66 \pm 6,69 \mathrm{D} \mathrm{a}$ & $10,66 \pm 0,06,00 \mathrm{D}$ c & $17,33 \pm 5,3400$ \\
5 & $46,67 \pm 3,95 \mathrm{C} \mathrm{a}$ & $23,33 \pm 9,34 \mathrm{C} \mathrm{c}$ & $39,33 \pm 2,45 \mathrm{C} \mathrm{b}$ \\
7,5 & $77,30 \pm 3,09 \mathrm{~B} \mathrm{a}$ & $56,00 \pm 3,57 \mathrm{~B} \mathrm{~b}$ & $57,33 \pm 4,76 \mathrm{~B} \mathrm{~b}$ \\
10 & $94,00 \pm 2,44 \mathrm{~A} \mathrm{a}$ & $79,33 \pm 4,48 \mathrm{~A} \mathrm{~b}$ & $76,66 \pm 3,65 \mathrm{~A} \mathrm{~b}$ \\
\hline
\end{tabular}

Extrato metanólico (EM); Extrato etanólico (EE) e Extrato de acetato de etila (EAE). Percentual de mortalidade média \pm desvio padrão. Médias seguidas de letras minúsculas nas linhas e maiúsculas nas colunas iguais não diferem pelo teste de Kruskal-Wallis (p>0,05). *Para comparação do controle foi utilizado teste de Ducan. Fonte: Autores.

Não foram encontrados na literatura estudos utilizando extratos vegetais de Ilex spp. avaliando a atividade acaricida dos mesmos. Os melhores resultados apresentados pelo EM pode estar relacionado à presença de taninos em sua composição fitoquímica. Alguns bioensaios foram conduzidos por Baran et al., 2020 por contato do ácaro D. gallinae com o extrato de Trachyspermum ammi e demonstrou que houve baixa mortalidade (45,8\%).

Os taninos presentes no EM apresentam habilidade de ligar-se com proteínas e macromoléculas apresentando atividades tóxicas, além de serem adstringentes, sua toxicidade varia de acordo com o peso da molécula, quanto mais pesado maior efeito tóxico (Monteiro et al., 2005). Além disso, podem se mostrar benéficos para a saúde, diversos estudos apontam atividade biológica comprovada como antioxidante (Smirnova et al., 2009), bactericida (Banso; Adeyemo, 2007), nematocida (Alonzo-Diaz et al., 2008), inseticida (Corrêa; Salgado, 2011) e acaricida contra Rhipicephalus (Boophilus) microplus (Fernandez-Sala et al., 2011), porém não foram encontrados na literatura estudos que esclareçam o modo de ação dos taninos sobre o ácaro, com isso este estudo sugere que a sua presença possa ser um aditivo interessante no controle de ácaros. O efeito acaricida pode ocorrer por diferentes mecanismos, como por exemplo, inibição da alimentação, oviposição e crescimento, 
alterações biológicas ou mesmo mortalidade. Neste contexto, o aumento de estudos utilizando produtos de origem vegetal para o combate do ácaro é de interesse comercial como uma alternativa aos acaricidas sintéticos, que podem causar problemas de contaminação ambiental e promover o desequilíbrio biológico do ecossistema (Ferraz et al., 2017).

O uso de pesticidas convencionais no manejo de pragas está enfrentando problemas como o desenvolvimento de resistência a pragas, poluição ambiental e impacto na saúde humana, juntamente com obstáculos regulatórios para aprovação e comercialização de novos pesticidas ecológicos, em conformidade com a tendência global de produtos livres de resíduos gêneros alimentícios. Nesse contexto, os pesticidas botânicos representam produtos alternativos valiosos a serem explorados (Baran et al., 2020).

\section{Considerações Finais}

Os extratos de I. brevicuspis demonstraram por meio da determinação fitoquímica a presença dos grupos saponinas, esteroides e taninos. A atividade antimicrobiana sobre as cepas padrão e de Salmonella foi satisfatória permitindo o controle de crescimento bacteriano. O EM apresentou a melhor percentagem antioxidante de $81,45 \%$ quando aplicado a $10 \mathrm{mg} / \mathrm{mL}$, e também demonstrou maior eficiência em relação a atividade acaricida quando aplicado a concentrações de 10\% e 7,5\%. Os resultados indicam o potencial biológico e biotecnológico de I. brevicuspis, podendo agregar valor a uma espécie nativa brasileira, dessa forma, como sugestão para futuros artigos, a investigação posterior mais aprofundada para identificar e isolar os bioativos vegetais responsáveis pela elevada atividade antimicrobiana e antioxidante observada nesta pesquisa.

\section{Agradecimentos}

Agradecemos ao Conselho Nacional de Desenvolvimento Cientítico e Tecnológico (CNPq) e Fundação Araucária pelo financiamento da pesquisa e a Coordenação de Aperfeiçoamento de Pessoal de Nível Superior (CAPES) pela concessão da bolsa de mestrado e ao Programa de Pós-graduação em Manejo e Conservação de Recursos Naturais (PPRN).

\section{Referências}

Arçari, D. P., Barthchewsky, W., Santos, T. W., Oliveira, K. A., Funck A., Pedrazzoli, J., Edrazzoli, J., Souza, M. F. F., Saad, M. J., Bastos, D. H. M., Gambero, A., Carvalho, P. O. \& Ribeiro, M. L. (2009). Antiobesity effects of yerba maté extract (Ilex paraguariensis) in high-fat diet-induced obese mice. Obesity (Silver Spring, Md.), 17(12), 2127-2133. 10.1038/oby.2009.158.

Alonso-Días, M. A., Torres-Acosta, J. F. J., Sandoval-Castro, C. A., Aguilarcaballero, A. J. \& Hoste, H. (2008). In vitro larval migration and kinetics of exsheathment of Haemonchus contortus larvae exposed to four tropical tanniniferous plant extracts. Veterinary Parasitology, 153, 313-319. 10.1016/j.vetpar.2008.01.042.

Banso, A. \& Adeyemo, S. O. (2007). Evaluation of antibacterial properties of tannins isolated from Dichrostachys cinerea. African Journal of Biotechnology, 15, 1785-1787. 10.5897/AJB2007.000-2262.

Baran, A. I., Jahanghiri, F., Hajipour, N., Sparagano, O. A. E., Norouzi, R. \& Moharramnejad, S. (2020). In vitro acaricidal activity of essential oil and alcoholic extract of Trachyspermum ammi against Dermanyssus gallinae. Veterinary parasitology 278, 1-7. 10.1016/j.vetpar.2020.109030.

Brenes, A. \& Roura, E. (2010). Essential oils in poultry nutrition: main effects and modes of action. Animal Feed Science and Technology, 158, 1-14. 10.1016/j.anifeedsci.2010.03.007.

Cabana, R., Silva, L. R., Valentao, P., Viturro, C. I. \& Andrade, P. B. (2013). Effect of different extraction methodologies on the recovery of bioactive metabolites from Satureja parvifolia (Phil.) Epling (Lamiaceae). Industrial Crops and Products, 48, 49-56. 10.1016/j.indcrop.2013.04.003.

CLSI. M07-A10: Methods for Dilution Antimicrobial Susceptibility Tests for Bacteria That Grow Aerobically; Approved Standard-Tenth Edition. CLSI (Clinical and Laboratory Standards Institute), 35(2). https://doi.org/10.1007/s00259-009-1334-3

Costa, D. E. M., Racanicci, A. M. C. \& Santana, A. P. (2017). Atividade antimicrobiana da erva-mate (Ilex paraguariensis) contra microrganismos isolados da carne de frango. Ciência Animal Brasileira, 18, 1-7. 10.1590/1089-6891v18e-42254

Corrêa, J. C. R. \& Salgado, H. R. N. (2001). Atividade inseticida das plantas e aplicações: revisão. Revista Brasileira de Plantas Medicinais, 500-506. $10.1590 /$ S1516-05722011000400016. 
Efing, L. C., Caliari, T. K., Nakashima, T. \& De Freitas, R. J. S. (2009). Caracterização química e capacidade antioxidante da erva-mate (Ilex paraguariensis st. Hil.). Boletim do Centro de Pesquisa de Processamento de Alimentos, 27(2). 10.5380/cep.v27i2.22034.

Fascina, V. B. (2011). Aditivos fitogênicos e ácidos orgânicos em dietas de frangos de corte. (Tese de doutorado), Universidade Estadual Paulista, São Paulo.

Fernández-Agulló, A., Pereira, E., Freire, M. S., Valentão, P., Andrade, P. B., González Álvarez, J. A. \& Pereira, J. A. (2013). Influence of solvent on the antioxidant and antimicrobial properties of walnut (Juglans regia L.) green husk extracts. Industrial Crops and Products, 42, 126-132. 10.1016/j.indcrop.2012.05.021.

Ferraz, J. C. B., Matos, C. H. C., Oliveira, C. R. F., Sá, M. G. R. \& Conceição, A G C. (2017). Extrato de folhas de juazeiro com atividade acaricida sobre o ácaro-vermelho em algodoeiro. Pesquisa Agropecuária Brasileira, 52(7), 493-499. 10.1590/s0100-204x2017000700003.

Filip, R. M. S., Lotito, S. B., Ferraro, G. M. S. \& Fraga, C. G. (2000). Antioxidant activity of Ilex paraguariensis and related species. Nutrition Research, 20(10),1437-144. 10.1016/S0271-5317(00)80024-X.

Flochlay AS, Thomas E, Sparagano O (2017) Poultry red mite (Dermanyssus gallinae) infestation: a broad impact parasitological disease that still remains a 546 significant challenge for the egg-laying industry in Europe. Parasit Vectors 10:357. 10.1186/s13071-017-2292-4.

Freitas, R. C., Rocha, T. J. M., Azevedo, R. R. D. S., Souza, L. I. O. \& Santos, A. F. (2014). Avaliação da atividade antimicrobiana e antioxidante das espécies Plectranthus amboinicus (lour.) e mentha x villosa (huds.). Revista de Ciências Farmacêuticas Básica e Aplicada, 35(1), 113-118. ISSN 1808-4532

Gobbo-Neto, L. \& Lopes, N P. (2007). Plantas medicinais: fatores de influência no conteúdo de metabólitos secundários. Química Nova, 30(2), 374-381. $10.1590 /$ S0100-40422007000200026.

Gonçalves, J. H. T., Santos, A. S. \& Morais, H. A. (2015). Atividade antioxidante, compostos fenólicos e triagem fitoquímica de ervas condimentares desidratadas. Revista da Universidade Vale do Rio Verde, 13(1), 486-497. 10.5892/ruvrd.v13i1.2003.

Guilarducci, N. V., Araújo, S. G., Pereira, A. F., Ribeiro, R. I. M. A., Dos Santos Lima, L. A. R. \& Pinto, F. C. H. (2016). Efeito da administração oral de extrato etanólico de Rosmarinus officinalis 1. (alecrim) no desenvolvimento do tumor sólido de Ehrlich. Revista Fitos, 10(1), 23-29. 10.5935/24464775.20160003.

Gyawali, R. \& Ibrahim, S. A. (2014). Natural products as antimicrobial agents. Food Control, 46, 412-429. 10.1016/j.foodcont.2014.05.047.

Heck, C. I. \& De Meija, E. G. (2007). Yerba Mate Tea (Ilex paraguariensis): A Comprehensive Review on Chemistry, Health Implications, and Technological Considerations. Journal of Food Science, 72(9), 138-151. 10.1111/j.1750-3841.2007.00535.x

Lima, I. P. A., Alves, R. A. H., Costa, M. R. M., Mendonça, A. K. P., Lima, E. L. F., Langassner, S. M. Z., Dametto, F. R., Lima, K. C. \& Lins, R. D. A. (2021). Antimicrobial activity of Spondias mombin L. aqueous and hydroethanolic extracts on Enterococcus faecalis and Pseudomonas aeruginosa - an in vitro study. Research, Society and Development, 10(1), 1-13. 10.33448/rsd-v10i1.11949.

Loureiro, R. J., Roque, F., Rodrigues, A. T., Herdeiro, M. T. \& Ramalheira, E. (2016). O uso de antibióticos e as resistências bacterianas: breves notas sobre a sua evolução. Revista Portuguesa de Saúde Pública, 34(1), 77-84. 10.1016/j.rpsp.2015.11.003.

Matos, F. J. A. (1997). Introdução a fitoquímica experimental. Edições UFC.

Mendez, M., Rodríguez, R., Ruiz, J., Morales-Adame, D., Castillo, F., Hernández-Castillo, F. D. \& Aguilar, C N. (2012). Antibacterial activity of plant extracts obtained with alternative organics solvents against food-borne pathogen bacteria. Industrial Crops and Products, 37(1) 445-450. 10.1016/j.indcrop.2011.07.017.

Monteiro, J. M., Albuquerque, U. P. \& Araujo, E L. (2005). Taninos: uma abordagem da química à ecologia. Química Nova, 28(5) 892. 10.1590/S010040422005000500029 .

Onivogui, G., Letsididi, R., Diaby, M., Wang, L. \& Song, Y. (2016). Influence of extraction solvents on antioxidant and antimicrobial activities of the pulp and seed of Anisophyllea laurina R. Br. ex Sabine fruits. Asian Pacific Journal of Tropical Biomedicine, 6(1), 20-25. 10.1016/j.apjtb.2015.09.023.

Pandini, J. A., Pinto, F. G. S., Scur, M. C., Alves, L. F. A. \& Martins, C. C. (2015). Antimicrobial, insecticidal, and antioxidant activity of essential oil and extracts of Guarea kunthiana A. Juss. Journal of Medicinal Plants Research, 9(3) 48-55. 10.5897/JMPR2014.5551.

Pereira, A. S., Shitsuka, D. M., Parreira, F. J., \& Shitsuka, R. (2018). Metodologia da Pesquisa Científica. [e-book]. (1ª ed). Santa Maria: UAB/NTE/UFSM. Disponível em: https://repositorio.ufsm.br/bitstream/handle/1/15824/Lic_Computacao_Metodologia-Pesquisa -Cientifica.pdf.sequence=1. Acesso em: 28fev. 2021.

Pereira, D. (2011). Dermanyssus gallinae em galinhas poedeiras em bateria: Carga parasitária, acção vectorial e ensaio de campo de um biopesticida. (Dissertação de Mestrado), Universidade Técnica de Lisboa-Faculdade de Medicina Veterinária, Lisboa.

Rufino, M. S. M., Alves, R. E., Brito, E. S., Morais, S. M., Sampaio, C. G., Jimenez, J. P. \& Calixto, F. D. S. (2007). Determinação da atividade antioxidante total em frutas pela captura do radical livre DPPH. Embrapa, 127,1-4. ISSN 1679-6535.

Santos, A. T. L., Carneiro, J. N. P., Andrade-Pinheiro, J. C., Araújo-Neto, J. B., Sales, D. L., Freitas, M. A., Almeida-Bezerra, J. W. A., Batista, F. L. A., Magalhães, F. E. A., Pereira, C. C. S. S., Torres, M. L. A. L., Lima, E. E., Coutinho, H. D. M. \& Morais-Braga, M. F. B. (2020). Antibacterial and antioxidant potential of Spondias tuberosa Arruda (Anacardiaceae) extracts. Research, Society and Development 9(12), 1-21. 10.33448/rsd-v9i12.10845.

Scur, M. C., Pinto, F. G. S., Bona, E. A. M., Weber, L. D., Alves, L. F. A. \& Moura, A C. (2014). Occurrence and antimicrobial resistance of Salmonella serotypes isolates recovered from poultry of Western Paraná, Brazil. African Journal of Agricultural Research, 9(9), 823-830, 2014. 10.5897/AJAR2013.8202. 
Research, Society and Development, v. 10, n. 3, e10210313154, 2021

(CC BY 4.0) | ISSN 2525-3409 | DOI: http://dx.doi.org/10.33448/rsd-v10i3.13154

Smirnova, G. V., Vysochina, G. I., Muzyka, N. G., Samoilova, Z., Kukushkina, T. A. \& Oktabr'skii, O. N. (2009). The antioxidant characteristics of medicinal plant extracts from western Siberia. Applied Biochemistry and Microbiology, 45, 638-641. 10.1134/S0003683809060118.

Taketa, A. T. C., Gondorf, M., Breitmaier, E. \& Schenkel, E. P. (2002). New triterpene and triterpenoid glycosides from Ilex brevicuspis. Revista Brasileira de Ciências Farmacêuticas, 38 (2), 155-161. 10.1590/S1516-93322002000200004.

Weber, L. D., Pinto, F. G. S., Scur, M. C., Souza, J. G. L., Costa, W. F. \& Leite, C W. (2014). Chemical composition and antimicrobial and antioxidant activity of essential oil and various plant extracts from Prunus myrtifolia (1.) Urb. African Journal of Agricultural Research, 9(9), 846-853. 10.5897/AJAR2013.8260. 